\title{
The i-REACH Project in Cambodia
}

\author{
Kim Dara \\ <kimdara2001@yahoo.com> \\ Long Dimanche \\ <dimanche.long@gmail.com> \\ Seán Ó Siochrú \\ <sean@nexus.ie>
}

The i-REACH (Informatics for Rural Empowerment and Community Health) project in Cambodia is nothing if not ambitious ${ }^{1}$. The goal is to create the basis for communityowned ICT enterprises for rural areas, providing voice, data and content services - including community radio and video - to the local people at affordable rates and tailored to local needs. The community-owned telecommunications cooperative is not a new idea - consider the many hundreds of rural telephony cooperatives in the USA alone, and other diverse examples around the world ${ }^{2}$. Many emerging community wireless initiatives could be similarly characterised. However, Cambodia is a particularly challenging environment to work in, with a centralised state machinery, limited ICT and optical fibre infrastructure, and many areas lacking basic services such as water and electricity. Rural communities are characterised by high levels of poverty and illiteracy, and a very poorly organised civil society still suffers the traumas of Cambodia's history. That the project was launched at all is testimony to the willingness of Canada's IDRC (International Development Research Centre) to work in difficult environment, and the presence of progressive elements in Cambodia determined to build a better future.

i-REACH is a three year programme funded by the IDRC and run by the Ministry of Commerce in Cambodia. Ultimately, its goal is to generate and document research results that can be applied more widely. It achieves this through nurturing two Pilot community-driven ICT enterprises into existence that can greatly improve communications internally and externally, enhance economic, social and education facilities, and generate opportunities for micro-enterprises. In the latter stages, iREACH will engage in policy-influencing activities that hopefully will see the pilot projects' successes replicated within Cambodia and more widely.

Begun in May $1^{\text {st }} 2006$, the plan for each pilot is to have a dozen or so Village Hubs dotted around an area about 20 kilometres wide, located in publicly accessible buildings such as commune (local government) offices, health centres, pagodas and schools, each with a computer and staffed by a local Community Facilitator. These are linked together through a backbone wireless network centred on the Pilot HQ where additional computers with training and other facilities are located, alongside a community radio station serving the area and run by locals. Spread out up to a kilometre away from each of the Village Hubs are a number of (fixed) telephones - perhaps half a dozen - linked via WiFi to the Hub and by VoIP to all other phones, each in a location that allows for use by the public. Each Pilot is connected to the outside world initially via satellite, with the capacity to interconnect into mobile and fixed telephony networks.

\footnotetext{
${ }^{1}$ The i-REACH Website is at http://www.ireach.org. kh/

${ }^{2}$ See Seán Ó Siochrú, Bruce Girard (2005). Community-based Networks and Innovative Technologies: new models to serve and empower the poor. New York. UNDP http://www.propoor-ict.net/
} 
Thus, each Pilot is intended to be a mini rural network with several dozen telephones accessible to local people, computers and internet training in Village Hubs no more than an hour's walk away, a range of services focusing on local needs - health, education, agriculture, fishing, services etc. - available and supported; all of it animated by its own community radio station and most of it powered by solar or other sustainable energy sources. Over time and as regulation permits the initiative could begin to generate income from telephony and other services and ultimately become a sustainable enterprise owned and run by the villages with the potential to expand into neighbouring areas and, with appropriate policy and regulatory support, be replicated elsewhere. Behind it all is the idea that low cost wireless technologies, that are scaleable and easy to maintain, have the potential to revolutionise our approach to the provision of rural ICTs.

So goes the theory. And so, hopefully, will eventually go the practice. In the meantime, however, the i-REACH team is confronting some of the realities of attempting such an ambitious project in an environment where there is high mobility among a young workforce and where suitably trained and experienced researchers are rare. The project is already several months behind its overly optimistic schedule.

The two pilot areas comprise several communes around Kep, a coastal fishing and farming area in the south; and around Kamchai Mear, an agricultural district in the east near the border with Vietnam. They were selected during the preparatory phase of the Project for a number of reasons including a reasonable proximity to Phnom Penh, political support for their development, their contrasting economic basis and locations, and in one case the presence of a rural university. Led by two very committed Khmers, and guided by the IDRC and an external adviser, the preparatory phase took almost nine months. During the course of that time the Ministry to be responsible for the project was identified and negotiations concluded, the Director was appointed, the Manager and external consultants lined up, and organisations identified to support and manage each Pilot (Maharishi Vishnu University in Kamchay Mear, and a Cambodian NGO in the case of Kep). The final project document was designed involving all partners, and submitted to the IDRC for approval.

At launch, a daunting set of tasks confronted the Team, comprised at that point of the Director, Manager and several advisors. Recruitment of the Central and Pilots teams was the first obstacle. Drawing up terms of reference, advertising, and dealing with the enormous number of applications took no longer than usual, about two months. However, finding high quality and committed staff, willing to work in rural areas, is difficult in Cambodia given the limited pool of third level graduates, especially with experience. Despite a major effort in formal recruitment, most staff were in the end identified by informal means, through the team networking with those involved in development. While effective, and the quality of the team is perhaps now the project's greatest asset, this approach was slow in filling all the positions, and a gender balance was unfortunately not achieved. At the central level the main jobs filled were a Research Manager and a Webmaster (the latter left to study abroad after a few months - a not infrequent problem). Among the Pilots, recruitment of Pilot Coordinators, Research Coordinators, and Multi-Media Coordinators stretched well into 2007. Ongoing capacity building is also a central concern for i-REACH, right down to the local village staff and volunteers, and a concerted effort is underway to enable the entire team to develop their skills and teamwork capabilities.

As the teams were gradually forming, work began on baseline research and on participatory methods of determining local needs and interests, led by external advisers and overseen by the Research Manager and Pilot Coordinators. This yielded useful results and was also a positive process within the community. An early milestone was the creation of an Interim Pilot Committee in Kamchay Mear, using a transparent and democratic process of election, comprising a gender balanced and diverse group of local villagers. The process 
significantly enhanced the standing of the Project locally. A similar process followed later in Kep. The Kep pilot suffered overall delays because the initial institution identified to oversee the Pilot backed out, and a new NGO had to be identified - the Centre for Social Development - and negotiations concluded.

A second major task at the Pilot level was the renovation and equipping of each Pilot $\mathrm{HQ}$, in buildings donated by the local government. Alongside this, the process of specifying the ICT technology requirements and engaging contractors for installation also began. The latter involved a number of components, each with it own issues: external connectivity, of which there were various options, none ideal and all expensive; the backbone network of the Pilots linking the Village Hubs; and the local WiFi networks interconnecting the voice phones, and networking the computers. Alongside was the radio station.

Both areas soon encountered delays. The intention was that funding would be found within Cambodia to renovate the offices, and general commitments were entered into. However the institutional and bureaucratic barriers were such that after long delays it was decided to go ahead using the project's own funds. Even then, finding suitably qualified builders was difficult in these rural areas.

The ICT infrastructure aspects were put to tender but a combination of inadequate specification of what was required, limited technical capabilities of supplier companies in Cambodia, and the generally slow pace of contract development there contrived to create one delay after another. Contracts were finally signed in May 2007, and work got underway. Furthermore, no progress at all was possible on building the radio station since a decision on the granting of a broadcast license by the appropriate Ministry is still pending.

Thus a year into i-REACH, progress on the ground, apart from the research and the formation of local Committees, has been minimal. Only in May 2007 was sufficient progress made to have the end (of the beginning) clearly in sight. In mid summer 2007, pilot staff (who had been making do in various locations) finally moved into their HQs, and they are now connected via satellite to the Internet. By late 2007 nine village hubs were connected to the broadband networks, each with its own local WiFi network. The Radio license remains stalled into 2008.

Even in the absence of such basics, the Teams pressed ahead as much as possible with the plans. From within the community, 'Content Developers' have been recruited in both areas and are working with Pilot Staff to create audio, video and internet content. Podcasting, vodcasting, and a 'village megaphone' system (used for instance in the Philippines) will substitute for the moment for full broadcast radio, and a few programmes might even be broadcast by a commercial station from a city close to Kep. With the internet in place, and content under development, villagers are finally seeing long-anticipated and long-promised benefits.

i-REACH's current committed funding is until April 2009 and it is now clear that accomplishing the targeted objectives will require more time. The obstacles faced up to now, serious as they are, were primarily to do with putting the prerequisites of the project in place. They bring i-REACH to the starting point in the community, deploying the physical tools. The next stage is even more daunting: on the one side, developing services and generating real benefits using these technologies: and on the other, building up the capacity of the local communities to actually develop, run and operate the 'hard' and 'soft' aspects of these initiatives. Community institution-building takes time and sustained commitment, from the external professionals introducing the activities into the area, but especially from the communities themselves. The enthusiasm of the local people to date, and their willingness to embrace news ideas and learn new skills, is heartening. 